\title{
Efficacy of different dose of dexmedetomidine combined with remifentanil in colonoscopy: a randomized controlled trial
}

\author{
Li Jia, Meng Xie, Jing Zhang, Jingyu Guo, Tong Tong and Yuying Xing ${ }^{*}$
}

\begin{abstract}
Background: Dexmedetomidine has advantages during colonoscopy as it allows the patient to cooperate during the procedure. Few studies examined the dexmedetomidine-remifentanil combination. This study was to evaluate the effects of different doses of the dexmedetomidine-remifentanil combination in colonoscopy.

Methods: This was a prospective trial carried out at the Fourth Hospital of Hebei Medical University between 02/ 2018 and 10/2018. The patients were randomized: group I (dexmedetomidine $0.2 \mu \mathrm{g} \cdot \mathrm{kg}^{-1}$ ), group II (dexmedetomidine $0.3 \mu \mathrm{g} \cdot \mathrm{kg}^{-1}$ ), and group III (dexmedetomidine $0.4 \mu \mathrm{g} \cdot \mathrm{kg}^{-1}$ ), all combined with remifentanil. The primary outcomes were the patient's body movements during the procedure and adverse events.

Results: Compared with at admission $\left(T_{0}\right)$, the SBP, HR, and RR at immediately after giving DEX $\left(T_{1}\right)$, at the beginning of the examination $\left(T_{2}\right), 5$ min after the beginning of the examination $\left(T_{3}\right), 10$ min after the beginning of the examination $\left(T_{4}\right)$, and at the end of the examination $\left(T_{5}\right)$ in the three groups were all reduced (all $P<0.05$ ), but all were within the clinically normal range. $\mathrm{SpO}_{2}$ remained $>98 \%$ in all patients during the examination. Compared with $T_{0}$, the BIS values of the three groups were decreased at $T_{1}$ and $T_{2}$ (all $P<0.05$ ). There were no significant differences in BIS among the three groups (all $P>0.05$ ). The minimum BIS value in group III was lower than in groups I and II $(P<0.05)$. The degree of satisfaction with the anesthesia effect was higher in groups II and III that in group I $(P<0.05)$. No hypotension occurred, seven patients had bradycardia, and four patients had nausea/ vomiting.

Conclusions: Dexmedetomidine $0.3 \mu \mathrm{g} \cdot \mathrm{kg}^{-1}$ combined with remifentanil was effective for colonoscopy and had few adverse reactions.

Chinese Clinical Trial Registry: ChiCTR2000029105, Registered 13 January 2020 - Retrospectively registered.
\end{abstract}

Keywords: Colonoscopy, Dexmedetomidine, Piperidines, Analgesia, Conscious sedation

\section{Background}

Colonoscopy can be performed for the screening of cancer, adenomas, and polyps, for the assessment of known or possible bleeding, and for the evaluation of possible

\footnotetext{
* Correspondence: 281575038@qq.com

Department of Anesthesiology, Fourth Hospital of Hebei Medical University, No. 12, Jiankang Road, Shijiazhuang 050000, Hebei, China
}

causes of abdominal pain, gastrointestinal symptoms, and/or changes in bowel habits [1, 2]. The National Colorectal Cancer Roundtable aims to reach $80 \%$ screening prevalence in the eligible American population [3, 4], representing 5.1 million colonoscopies each year [5].

Beyond the discomfort and inconveniences associated with bowel preparation [6], colonoscopy is

(c) The Author(s). 2020 Open Access This article is licensed under a Creative Commons Attribution 4.0 International License, which permits use, sharing, adaptation, distribution and reproduction in any medium or format, as long as you give appropriate credit to the original author(s) and the source, provide a link to the Creative Commons licence, and indicate if changes were made. The images or other third party material in this article are included in the article's Creative Commons licence, unless indicated otherwise in a credit line to the material. If material is not included in the article's Creative Commons licence and your intended use is not permitted by statutory regulation or exceeds the permitted use, you will need to obtain permission directly from the copyright holder. To view a copy of this licence, visit http://creativecommons.org/licenses/by/4.0/ The Creative Commons Public Domain Dedication waiver (http://creativecommons.org/publicdomain/zero/1.0/) applies to the data made available in this article, unless otherwise stated in a credit line to the data. 
associated with discomfort and sometimes pain. At present, the commonly used methods are the intravenous injection of propofol, etomidate, ketamine, and other drugs to make the patient's unconscious [7]. The disadvantage is that the patient cannot cooperate during the examination (e.g., for changing position), and medical staff is needed to assist in turning over the patient, if necessary. This may compress the patient's stomach and abdomen, which may cause gastric reflux and aspiration, which may cause pneumonia, with morbidity and even mortality $[8,9]$.

Dexmedetomidine (DEX) is a new type of highly selective $\alpha 2$ receptor agonist. It has sedative, analgesic, and anxiolytic effects, and is known as a "wake-up sedative". Compared with propofol and fentanyl, it provides sedation without the risk of respiratory depression and can provide cooperative or semi-rousable sedation $[10,11]$. It has incomparable advantages during colonoscopy as it allows the patient to cooperate during the procedure [12-15]. Dexmedetomidine can be used with other drugs such as remifentanil to achieve deeper sedation, but few studies examined the dexmedetomidine-remifentanil combination for colonoscopy.

Therefore, this study aimed to evaluate the effects of dexmedetomidine combined with remifentanil at different doses for colonoscopy. The results could provide clues about the most optimal doses and improve the patient experience of colonoscopy.

\section{Methods}

\section{Study design and patients}

This was a prospective trial that was carried out in patients who were scheduled to undergo colonoscopy at the Fourth Hospital of Hebei Medical University between February 2018 and October 2018. All patients were inpatients. This study was approved by the Medical Ethics Committee of the Fourth Hospital of Hebei Medical University (2017MEC113) and written informed consent was obtained from all subjects participating in the trial. The trial was registered at the Chinese Clinical Trial Registry (ChiCTR2000029105, Principal investigator: Li Jia, Date of registration: 2020-01-13). This study adheres to CONSORT guidelines.

The inclusion criteria were: 1) ASA grade was I-II; 2) $18-75$ years of age; 3) weight of $50-80 \mathrm{~kg}$; 4) no obvious abnormalities in preoperative ECG, blood routine, electrolytes, and other tests; 5) no history of allergies to narcotic drugs; 6) no history of sedation, analgesics, or alcohol abuse; and 7) no mental illness. The exclusion criteria were: 1 ) emergency patients; 2) severe abnormalities in heart, lung, kidney, liver, and other functions; 3 ) sleep apnea syndrome or difficult airways; 4) bronchial asthma; or 5) recent respiratory infections.

\section{Grouping and intervention}

The patients were randomly divided into three groups using the random number table method: group I (DEX $0.2 \mu \mathrm{g} \cdot \mathrm{kg}^{-1}$ ), group II (DEX $0.3 \mu \mathrm{g} \cdot \mathrm{kg}^{-1}$ ), and group III (DEX $0.4 \mu \mathrm{g} \cdot \mathrm{kg}^{-1}$ ) (Fig. 1). Patients, surgeon and postoperative observes were blind to group allocation. The routine preoperative preparation was performed. The patient was placed on the left side with the knees bent after entering the room. The Bene View T5 monitor (Mindray Biomedical Electronics Co., Shenzhen, China) and Aspect 2000 EEG monitor (Aspect Medical Systems, Inc., Newton, MA, USA) were connected to monitor the systolic blood pressure (SBP), diastolic blood pressure (DBP), heart rate (HR), pulse oximetry $\left(\mathrm{SpO}_{2}\right)$, respiratory rate (RR), and bispectral index (BIS). Oxygen mask inhalation was given at $5 \mathrm{~L} / \mathrm{min}$. An upper limb venous access was opened. For group I, $0.2 \mu \mathrm{g} \cdot \mathrm{kg}^{-1}$ DEX (batch number: 10122334, Jiangsu Hengrui Pharmaceutical Co., Ltd.) and a loading dose of $1 \mu \mathrm{g} \cdot \mathrm{kg}^{-1}$ remifentanil (batch number: 6120721 Yichang Renfu Pharmaceutical Co., Ltd.) was injected successively, both within 2 min with an intravenous pump. Then, remifentanil was given at a maintenance dose of $0.1 \mu \mathrm{g} \cdot \mathrm{kg}^{-1} \cdot \mathrm{min}^{-1}$. Colonoscopy started after $2 \mathrm{~min}$. The infusion of remifentanil was stopped after the end of colonoscopy. For group II, the patients were injected intravenously with $0.3 \mu \mathrm{g} \cdot \mathrm{kg}^{-1}$ DEX. The patients in group III were injected intravenously with $0.4 \mu \mathrm{g} \cdot \mathrm{kg}^{-1}$ DEX. The dose of remifentanil was the same in all three groups. If bradycardia occurred during the examination ( $\mathrm{HR}<50$ beats/min), atropine $0.5 \mathrm{mg}$ was injected intravenously. Ephedrine $5-10 \mathrm{mg}$ was injected intravenously if hypotension (SBP $<90 \mathrm{mmHg}$ ) appeared. And after the colonoscopy, patients were monitored in PACU for $30 \mathrm{~min}$ and transferred to the ward.

\section{Data collection}

The data of patients, including SBP, DBP, $\mathrm{HR}, \mathrm{SpO}_{2}$, and RR at admission $\left(\mathrm{T}_{0}\right)$, immediately after giving $\mathrm{DEX}$ $\left(\mathrm{T}_{1}\right)$, at the beginning of the examination $\left(\mathrm{T}_{2}\right), 5 \mathrm{~min}$ after the beginning of the examination $\left(\mathrm{T}_{3}\right), 10 \mathrm{~min}$ after the beginning of the examination $\left(\mathrm{T}_{4}\right)$, and at the end of the examination $\left(\mathrm{T}_{5}\right)$, and the BIS value at $\mathrm{T}_{0}, \mathrm{~T}_{1}$, and $\mathrm{T}_{2}$, and the minimum value of BIS during the examination were recorded. We investigated whether the patient was cooperating quietly and whether there were body movements during the examination; whether the patient could wake up; if the patient was needed to turn and whether the patient could do it on his own to complete the examination; number of patients with slight limb activity who did not need additional medications; number of patients with great limb mobility who were unable to cooperate quietly and complete the examination and required additional medications (intravenous injection of $50 \mathrm{mg}$ propofol); number of patients 


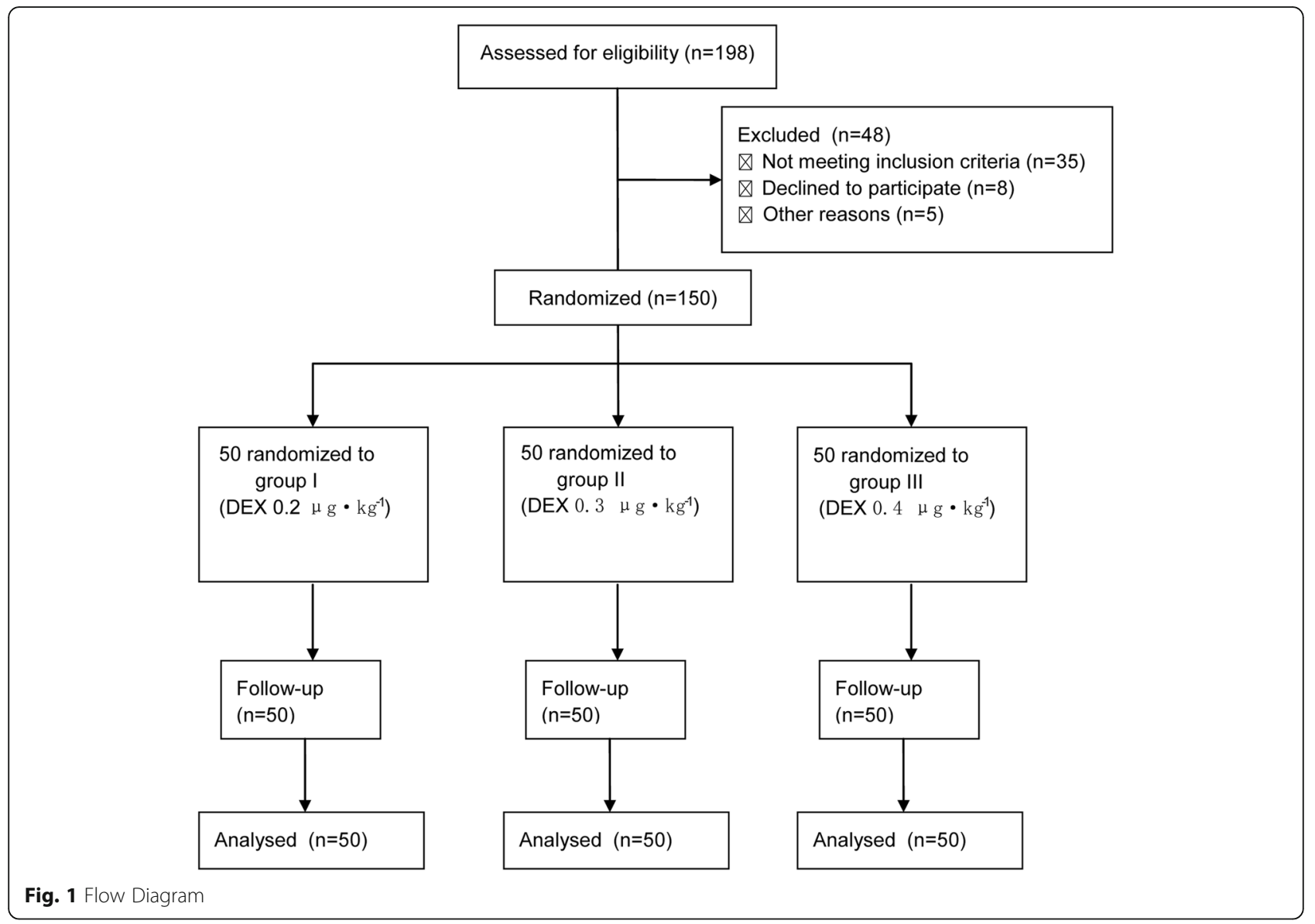

who could wake up; and number of patients who could turn over the body on their own and cooperate to the examinations were recorded. Adverse reactions such as bradycardia, hypotension, and nausea and vomiting were recorded. The examination duration was also recorded. At the end of the examination, the satisfaction degree of the surgeon on the anesthesia effect, which was divided into three grades of excellent, good, and poor, were investigated. Excellent: the patient was quiet during the examination, had no limb movement, was able to wake up during the operation, and was able to turn over the body to cooperate with the examination. Good: the patient had only slight limb movement, which did not affect the examination, was able to wake up during the operation and was able to turn over the body to cooperate with the examination. Poor: the patient had a large degree of limb activity, and it was difficult to complete the examination quietly or cooperatively, or the patient had no limb activity, but could not wake up, or could wake up but could not turn over the body to cooperate with the examination. All examinations were performed by a senior doctor in the endoscopy department of our hospital.

\section{Outcomes}

The primary outcomes of this study were the patient's body movements during the procedure and adverse events such as bradycardia, hypotension, nausea, and vomiting. The secondary outcomes were the duration of colonoscopy and the satisfaction of the surgeon to the anesthesia effect.

\section{Statistical analysis}

The sample size was calculated based on the patient's movements during the examination. Our preliminary study found that the incidence of patient movements in 11 patients with remifentanil for analgesia was $55 \%$. A reduction of $25 \%$ after combined with dexmedetomidine was considered clinically significant. Therefore, a minimum sample size of 46 patients for each group would be required with a significance level of $5 \%$ to achieve a power of $80 \%$. Taking into consideration a potential dropout rate of $10 \%$, we recruited 50 patients per group. Normally distributed continuous variables were presented as mean \pm standard deviation and were analysed using Student's t test. Mann-Whitney U test was used for non-normally distributed continuous variables, which 
were presented as median (interquartile range) $[\mathrm{M}(\mathrm{Q})]$. Categorical variables were expressed as frequency (percentage) and were analysed using the Pearson chi-square test. Wilcoxon rank sum test was used for comparison of rank variables. $p<0.05$ was statistically significant.

\section{Results}

\section{Characteristics of the participants}

There were no significant differences in general data (age, sex, weight, and examination duration) among the three groups (all $P>0.05$ ) (Table 1). There were no significant differences in SBP, DBP, $\mathrm{HR}$, and $\mathrm{RR}$ at $\mathrm{T}_{0}$ among the three groups (all $P>0.05$ ) (Table 2).

\section{Changes in circulation and breathing parameters}

Compared with $\mathrm{T}_{0}$, the SBP, HR, and RR at $\mathrm{T}_{1-5}$ in the three groups were all reduced (all $P<0.05$ ), but all were within the clinically normal range (Table 2, Fig. 2). $\mathrm{SpO}_{2}$ remained $>98 \%$ in all patients during the examination.

\section{Adverse reactions}

During the examination, 13, six, and three patients in groups I, II, and III, respectively, had slight body movements that did not interfere with the operation or required propofol injection (all $P<0.05$ ). Two patients in group I had body movements that interfered with the operation and needed additional propofol. All patients in each group can be waked up during the examination. For patients who needed to turn over, except for one patient in group III who needed assistance, all patients could turn over on their own. There were 0 , one, and six participants of bradycardia in groups I, II, and III, respectively (all $P<0.05$ ). No hypotension occurred in the three groups. Nausea and vomiting occurred in one participant in group I, one in group II, and two in group III (Table 3).

\section{Bispectral index}

Compared with $\mathrm{T}_{0}$, the BIS values of the three groups were decreased at $T_{1}$ and $T_{2}$ (all $P<0.05$ ). There were no significant differences in BIS among the three groups (all $P>0.05$ ). The minimum BIS value in group III was lower than in groups I and II $(P<0.05)$ (Table 4$)$.

\section{Surgeon's satisfaction}

Thirty-five participants in group I were excellent, 13 were good, and two were poor; those numbers were 44 , six, and 0 , respectively, in group II; and 47, three, and 0 , respectively, in group III. The degree of satisfaction with the anesthesia effect was higher in groups II and III that in group I $(P<0.05)$ (Table 5$)$.

\section{Discussion}

Dexmedetomidine has advantages during colonoscopy as it allows the patient to cooperate during the procedure $[12,13]$. Few studies examined the dexmedetomidine-remifentanil combination. Therefore, this study aimed to evaluate the effects of different doses of the dexmedetomidine-remifentanil combination in colonoscopy. The results strongly suggest that dexmedetomidine $0.3 \mu \mathrm{g} \cdot \mathrm{kg}^{-1}$ combined with remifentanil was effective for colonoscopy and had few adverse reactions.

Dexmedetomidine is a new type of highly selective $\alpha 2$ receptor agonist and has eight times the affinity to $\alpha 2$ receptors as clonidine $[10,11,16]$. Compared with clonidine, dexmedetomidine has stronger sedative, analgesic, and anxiolytic effects $[10,11,16]$. Its sedative and hypnotic characteristics are that the patients can be awakened and cooperate, and the sleep state is similar to that of natural sleep $[10,11,16]$. It is also the only sedative that allows patients to be easily awakened to cooperate without breathing depression $[10,11,16]$. Bekker et al. [17] reported for the first time the use of dexmedetomidine for craniotomy and left temporal tumor resection, during which it could be used to locate the language area and awaken intraoperatively during surgery. Ramsay et al. [18] used dexmedetomidine as the only intravenous anesthetic in the laser ablation for severe subglottic stenosis and artificial upper trachea replacement. The patients' blood oxygen saturation was above $90 \%$ without oxygen inhalation, and hemodynamics were relatively stable. The results of this study showed that the hemodynamic parameters and respiratory parameters of the three groups of participants were within the clinically normal range, and $\mathrm{SpO}_{2}$ was above $98 \%$ in all participants, which was consistent with the results of the above studies.

Cortinez et al. [19] showed that dexmedetomidine had mild-to-moderate analgesic effects on cold compression tests, but had limited effects on acute pain such as electricity and thermal pain. Its analgesic mechanism is different from opioids, which can have a synergistic effect and reduce the amount of opioids [20]. Therefore, the combination of dexmedetomidine and opioids can achieve the purpose of analgesia and

Table 1 Comparison of demographics and clinical characteristics of the three groups

\begin{tabular}{lllllll}
\hline Group & Cases & Age (years) & Weight $(\mathrm{kg})$ & ASA (I/ I) & Sex (male/female) & procedure time, min \\
\hline I & 50 & $53.4 \pm 3.3$ & $67.5 \pm 2.6$ & $20 / 30$ & $27 / 23$ & $20.3 \pm 1.4$ \\
II & 50 & $51.6 \pm 2.5$ & $63.3 \pm 1.8$ & $22 / 28$ & $26 / 24$ & $21.2 \pm 1.0$ \\
III & 50 & $55.8 \pm 2.8$ & $63.9 \pm 2.6$ & $19 / 31$ & $24 / 26$ & $20.7 \pm 1.2$ \\
\hline
\end{tabular}


Table 2 Hemodynamic and respiratory changes in the three groups

\begin{tabular}{|c|c|c|c|c|c|c|c|}
\hline Group & Items (mmHg/bpm) & $\mathrm{T}_{0}$ & $\mathrm{~T}_{1}$ & $\mathrm{~T}_{2}$ & $T_{3}$ & $\mathrm{~T}_{4}$ & $\mathrm{~T}_{5}$ \\
\hline \multirow[t]{4}{*}{ I } & SBP & $125 \pm 23$ & $111 \pm 22^{a}$ & $114 \pm 22^{a}$ & $112 \pm 23^{a}$ & $114 \pm 22^{a}$ & $116 \pm 24^{a}$ \\
\hline & $\mathrm{DBP}$ & $69 \pm 11$ & $62 \pm 12^{a}$ & $63 \pm 12^{a}$ & $63 \pm 12^{a}$ & $66 \pm 12$ & $69 \pm 16$ \\
\hline & $H R$ & $80 \pm 14$ & $74 \pm 14^{a}$ & $75 \pm 13^{a}$ & $73 \pm 12^{a}$ & $74 \pm 12^{a}$ & $76 \pm 12^{a}$ \\
\hline & $\mathrm{RR}$ & $18 \pm 2$ & $16 \pm 3^{a}$ & $16 \pm 3^{a}$ & $16 \pm 4^{a}$ & $16 \pm 4^{a}$ & $16 \pm 4^{a}$ \\
\hline \multirow[t]{4}{*}{$\|$} & SBP & $124 \pm 20$ & $111 \pm 19^{a}$ & $110 \pm 19^{a}$ & $112 \pm 20^{a}$ & $115 \pm 20^{a}$ & $117 \pm 22^{a}$ \\
\hline & DBP & $70 \pm 11$ & $64 \pm 11^{\mathrm{a}}$ & $64 \pm 11^{\mathrm{a}}$ & $65 \pm 12^{a}$ & $68 \pm 13$ & $70 \pm 14$ \\
\hline & $H R$ & $73 \pm 14$ & $67 \pm 12^{a}$ & $69 \pm 15^{a}$ & $72 \pm 16^{a}$ & $72 \pm 16^{a}$ & $73 \pm 16^{a}$ \\
\hline & $\mathrm{RR}$ & $18 \pm 2$ & $16 \pm 3^{a}$ & $15 \pm 3^{a}$ & $15 \pm 3^{a}$ & $15 \pm 2^{a}$ & $15 \pm 2^{a}$ \\
\hline \multirow[t]{4}{*}{ III } & SBP & $123 \pm 16$ & $117 \pm 21^{a}$ & $107 \pm 18^{a}$ & $99 \pm 18^{a}$ & $105 \pm 19^{a}$ & $106 \pm 18^{a}$ \\
\hline & DBP & $72 \pm 12$ & $70 \pm 14$ & $75 \pm 13^{a}$ & $73 \pm 12^{a}$ & $74 \pm 12^{a}$ & $76 \pm 12^{a}$ \\
\hline & $H R$ & $81 \pm 15$ & $72 \pm 13^{a}$ & $73 \pm 13^{a}$ & $75 \pm 13^{a}$ & $74 \pm 13^{a}$ & $75 \pm 13^{a}$ \\
\hline & $\mathrm{RR}$ & $18 \pm 3$ & $16 \pm 3^{a}$ & $15 \pm 3^{a}$ & $15 \pm 3^{a}$ & $15 \pm 3^{a}$ & $15 \pm 3^{a}$ \\
\hline
\end{tabular}

${ }^{\mathrm{a}} P<0.05$ vs. $\mathrm{T}_{0}$; all $P>0.05$ among the three groups for all parameters at all time points. $\mathrm{n}=50 /$ group

sedation. Remifentanil is a new type of short-acting $\mu$ opioid receptor agonist. Wilhelm et al. [21] reported that after remifentanil anesthesia, the patients could be waked up faster, and the orientation was recovered faster. Neurocognitive tests showed that it was better than fentanyl, which was more suitable for short outpatient surgery. Therefore, in this study, dexmedetomidine and remifentanil were used for painless colonoscopy. This combination has been reported before for colonoscopy [13], but the exact dose of dexmedetomidine has not been examined within the same trial.
The recommended dose of dexmedetomidine for general anesthesia is a loading dose not exceeding $1 \mu \mathrm{g} \cdot \mathrm{kg}^{-1}$. Due to the synergistic effect with remifentanil, the present study examined three doses $(0.2,0.3$, and $0.4 \mu \mathrm{g} \cdot \mathrm{kg}^{-1}$ ) combined with remifentanil $1-2 \mu \mathrm{g} \cdot \mathrm{kg}^{-1}$ and $0.1 \mu \mathrm{g} \cdot \mathrm{kg}^{-1} \cdot \mathrm{min}^{-1}$ maintenance dose [22]. Remifentanil at a rate of $0.1 \pm 0.05 \mu \mathrm{g} \cdot \mathrm{kg}^{-1} \cdot \mathrm{min}^{-1}$ did not affect ventilation and wakefulness [23]. Therefore, in this study, the loading dose of remifentanil was $1 \mu \mathrm{g} \cdot \mathrm{kg}^{-1}$, and the maintenance dose was $0.1 \mu \mathrm{g} \cdot \mathrm{kg}^{-1} \cdot \mathrm{min}^{-1}$. After remifentanil was given at a loading dose, the time to peak efficacy was $1.6 \mathrm{~min}$ [24]. Therefore, colonoscopy
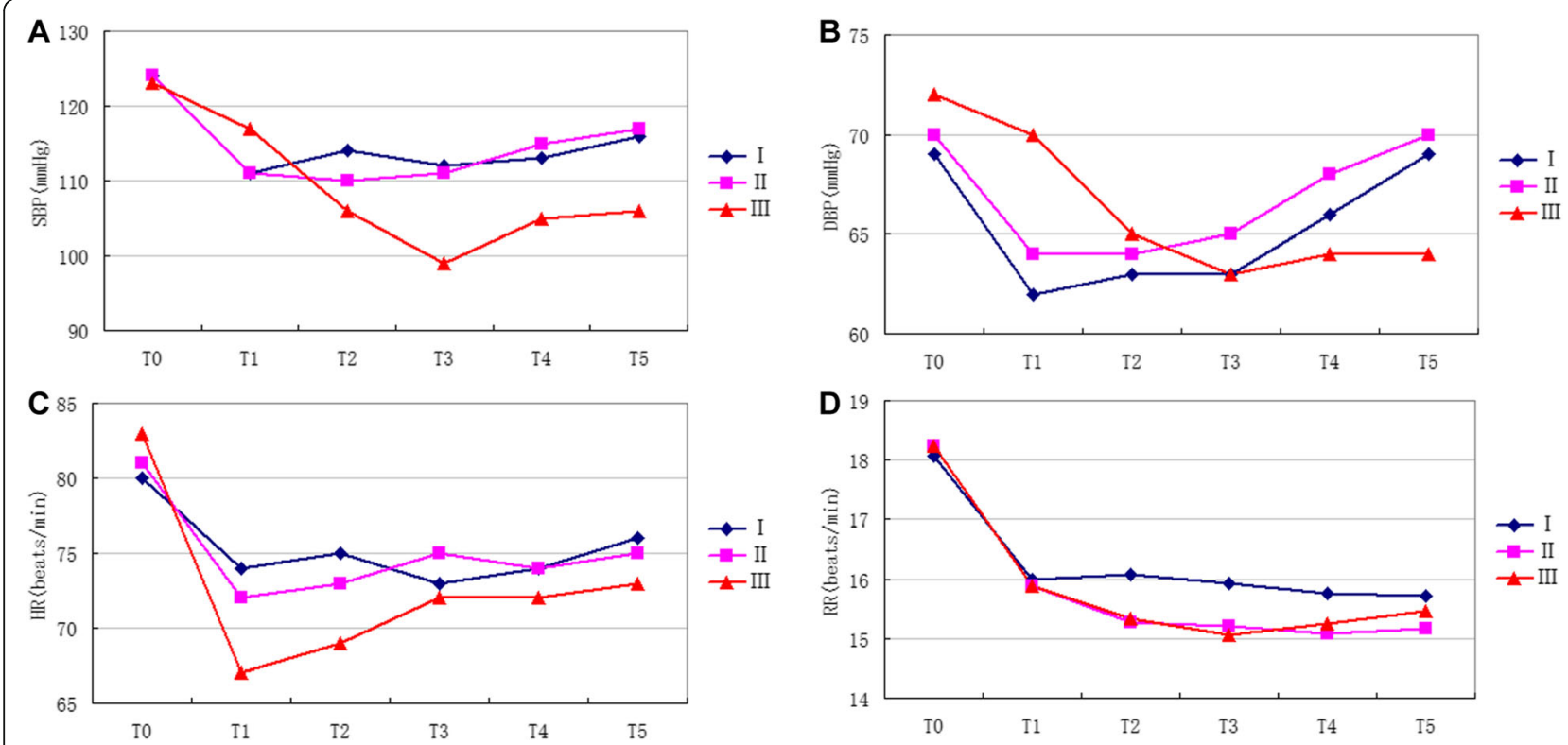

Fig. 2 A: Changes of SBP of three groups of patients. B: Fig. 2 Changes of DBP of three groups of patients. C: Fig. 3 Changes of HR of three groups of patients. D: Fig. 4 Changes of RR of three groups of patients 
Table 3 Comparison of the analgesic effect and occurrence of adverse events in the three groups

\begin{tabular}{llll}
\hline tems & Group I & Group I| & Group III \\
\hline Slight body movement & 13 & $6^{\mathrm{a}}$ & $3^{\mathrm{ab}}$ \\
Severe body movement & 2 & 0 & 0 \\
Could be awaked up & 50 & 50 & 50 \\
$\begin{array}{l}\text { Could change position independently } \\
\text { (patients need change position) }\end{array}$ & $8(8)$ & $11(11)$ & $8(9)$ \\
$\begin{array}{l}\text { Bradycardia } \\
\text { Hypotension }\end{array}$ & 0 & $1^{\mathrm{a}}$ & $6^{\mathrm{ab}}$ \\
Nausea and vomiting & 0 & 0 & 0 \\
\hline
\end{tabular}

${ }^{\mathrm{a}} P<0.05$ vs. group I; ${ }^{\mathrm{b}} P<0.05$ vs. group II

$\mathrm{n}=50 /$ group

started 2 min after the administration of remifentanil, and dexmedetomidine also began to have effect at this time since, after dexmedetomidine infusion, the rapid distribution-related half-life is about 6 min [25].

The results of the present study showed that only two patients in group I had body movements that interfered with the examination, but the examination could be completed after the addition of propofol. Both groups II and III achieved satisfactory analgesic effects, and the patients were quiet, with no or only mild body movements, which showed that dexmedetomidine combined with remifentanil was effective for analgesia during colonoscopy. The SBP, HR, and RR of the participants during the examination in the three groups were lower than before surgery. During the examinations, the minimum BIS value in the three groups was about 73, and all patients could wake up at any time. Except for one patient in group III who needed assistance for turning over, they could turn over on their own and cooperate to change the position. At the end of the examination, the rate of excellent and good anesthesia for groups II and III reached $100 \%$. This showed that dexmedetomidine combined with remifentanil was suitable for colonoscopy.

During the examination and after the operation, no hypotension occurred in the three groups, and the occurrence of nausea and vomiting was low, but the occurrence rate of bradycardia in group III was higher than that in groups I and II. Dexmedetomidine is a highly

Table 4 Comparison of the BIS values at different time points among the three groups

\begin{tabular}{|c|c|c|c|c|}
\hline Group & $\mathrm{T}_{0}$ & $\mathrm{~T}_{1}$ & $\mathrm{~T}_{2}$ & Minimum value \\
\hline 1 & $95.1 \pm 5.3$ & $91.5 \pm 8.2^{a}$ & $93.4 \pm 7.2^{a}$ & $86.7 \pm 7.5^{a}$ \\
\hline$\|$ & $96.4 \pm 2.2$ & $92.4 \pm 7.3^{a}$ & $92.5 \pm 6.7^{a}$ & $84.4 \pm 8.1^{a}$ \\
\hline III & $97.2 \pm 2.4$ & $92.2 \pm 8.5^{\mathrm{a}}$ & $88.3 \pm 9.2^{a}$ & $74.5 \pm 8.3^{a b c}$ \\
\hline
\end{tabular}

Table 5 Comparison of the satisfaction degree to the anesthesia effect of the surgeon among the three groups ( $n=$

\begin{tabular}{llll} 
50) & & & \\
\hline Group & Excellent & Good & Poor \\
\hline I & 35 & 13 & 2 \\
$\|$ & $44^{\mathrm{a}}$ & $6^{\mathrm{a}}$ & $0^{\mathrm{a}}$ \\
III & $47^{\mathrm{a}}$ & $3^{\mathrm{a}}$ & $0^{\mathrm{a}}$ \\
\hline $\begin{array}{l}\mathrm{a} P<0.05 \text { vs. group I } \\
\mathrm{n}=50 / \text { group }\end{array}$ & &
\end{tabular}

selective $\alpha 2$ receptor agonist, which activates postsynaptic $\alpha 2$ receptors in the central nervous system and simultaneously inhibits sympathetic nerve activity, causing lower blood pressure and heart rate.

During the examination, the minimum BIS value in groups I and II were decreased to about 86 , and the minimum BIS value in group III was about 73 . When all patients were waked up or talked to, the BIS value could return to more than 90. Except for one participant in group III who needed assistance, all the other patients were able to cooperate with the examiner to turn over the body on their own, and most patients did not experience any discomfort. It indicated that dexmedetomidine $0.2-$ $0.4 \mu \mathrm{g} \cdot \mathrm{kg}^{-1}$ could produce good sedation, which was consistent with the results of Souter et al. [26]. Nevertheless, the minimum BIS value in group III was lower than those in the other two groups, suggesting that $0.4 \mu \mathrm{g} \cdot \mathrm{kg}^{-1} \mathrm{dex}$ medetomidine combined with remifentanil had a risk of deeper sedation when used for colonoscopy.

This trial has limitations. It was performed at a single center. There was no control group. Only three doses of dexmedetomidine were tested, without changes in the dose of remifentanil. Finally, besides BIS, no objective score was used.

\section{Conclusions}

In conclusion, $0.3 \mu \mathrm{g} \cdot \mathrm{kg}^{-1}$ dexmedetomidine combined with remifentanil (loading dose of $1 \mu \mathrm{g} \cdot \mathrm{kg}^{-1}$, maintenance dose of $0.1 \mu \mathrm{g} \cdot \mathrm{kg}^{-1} \cdot \mathrm{min}^{-1}$ ) had a good effect, and few adverse reactions for colonoscopy.

\section{Abbreviations}

DEX: Dexmedetomidine; SBP: Systolic blood pressure; DBP: Diastolic blood pressure; HR: Heart rate; SpO2: Pulse oximetry; RR: Respiratory rate; BIS: Bispectral index

\section{Acknowledgments}

Not applicable.

\section{Authors' contributions}

$J L$ helped with study concept and design, acquisition of subjects and data, analysis and interpretation of data, and preparation of manuscript. XM helped with acquisition of subjects and data, analysis and preparation of manuscript. ZJ helped with acquisition of subjects and data and preparation of manuscript. GJ helped with study concept and design and preparation of manuscript. TT helped with acquisition of subjects and preparation of manuscript. XY helped with study concept and design, and interpretation of 
data, and preparation of manuscript. The authors read and approved the final manuscript.

\section{Funding}

Not applicable.

\section{Availability of data and materials}

The datasets used and/or analysed during the current study are available from the corresponding author on reasonable request.

\section{Ethics approval and consent to participate}

This study was approved by the Medical Ethics Committee of the Fourth Hospital of Hebei Medical University (2017MEC113) and written informed consent was obtained from all subjects participating in the trial. The trial was registered at the Chinese Clinical Trial Registry (ChiCTR2000029105, Principal investigator: Li Jia, Date of registration: 2020-01-13).

\section{Consent for publication}

Not applicable.

\section{Competing interests}

The authors declare that they have no competing interests.

Received: 18 May 2020 Accepted: 30 August 2020

Published online: 05 September 2020

\section{References}

1. Rex DK, Boland CR, Dominitz JA, Giardiello FM, Johnson DA, Kaltenbach T, et al. Colorectal cancer screening: recommendations for physicians and patients from the U.S. multi-society task force on colorectal cancer. Gastroenterology. 2017;153(1):307-23. https://doi.org/10.1053/j.gastro.2017 05.013 .

2. Wolf $A M D$, Fontham ETH, Church TR, Flowers CR, Guerra CE, LaMonte SJ, et al. Colorectal cancer screening for average-risk adults: 2018 guideline update from the american cancer society. CA Cancer J Clin. 2018;68(4):25081. https://doi.org/10.3322/caac.21457.

3. Meester RG, Doubeni CA, Zauber AG, Goede SL, Levin TR, Corley DA, et al. Public health impact of achieving $80 \%$ colorectal cancer screening rates in the United States by 2018. Cancer. 2015;121(13):2281-5. https://doi.org/10. 1002/cncr.29336.

4. Fedewa SA, Ma J, Sauer AG, Siegel RL, Smith RA, Wender RC, et al. How many individuals will need to be screened to increase colorectal cancer screening prevalence to 80\% by 2018? Cancer. 2015;121(23):4258-65. https://doi.org/10.1002/cncr.29659.

5. Joseph DA, Meester RG, Zauber AG, Manninen DL, Winges L, Dong FB, et al. Colorectal cancer screening: estimated future colonoscopy need and current volume and capacity. Cancer. 2016;122(16):2479-86. https://doi.org/ 10.1002/cncr.30070.

6. Johnson DA, Barkun AN, Cohen LB, Dominitz JA, Kaltenbach T, Martel $M$, et al. Optimizing adequacy of bowel cleansing for colonoscopy: recommendations from the us multi-society task force on colorectal cancer. Gastroenterology. 2014;147(4):903-24. https://doi.org/10.1053/j. gastro.2014.07.002.

7. Triantafillidis JK, Merikas E, Nikolakis D, Papalois AE. Sedation in gastrointestinal endoscopy: current issues. World J Gastroenterol. 2013;19(4): 463-81. https://doi.org/10.3748/wjg.v19.i4.463.

8. Green SM, Mason KP, Krauss BS. Pulmonary aspiration during procedural sedation: a comprehensive systematic review. Br J Anaesth. 2017;118(3):34454. https://doi.org/10.1093/bja/aex004.

9. Agrawal D, Marull J, Tian C, Rockey DC. Contrasting perspectives of anesthesiologists and gastroenterologists on the optimal time interval between bowel preparation and endoscopic sedation. Gastroenterol Res Pract. 2015;2015:497176. https://doi.org/10.1155/2015/497176.

10. Cormack JR, Orme RM, Costello TG. The role of alpha2-agonists in neurosurgery. J Clin Neurosci. 2005;12(4):375-8. https://doi.org/10.1016/j. jocn.2004.06.008

11. Pasin $L$, Greco T, Feltracco P, Vittorio A, Neto CN, Cabrini $L$, et al. Dexmedetomidine as a sedative agent in critically ill patients: a metaanalysis of randomized controlled trials. PLoS One. 2013;8(12):e82913. https://doi.org/10.1371/journal.pone.0082913.
12. Dere K, Sucullu I, Budak ET, Yeyen S, Filiz Al, Ozkan S, et al. A comparison of dexmedetomidine versus midazolam for sedation, pain and hemodynamic control, during colonoscopy under conscious sedation. Eur J Anaesthesiol. 2010;27(7):648-52. https://doi.org/10.1097/EJA.0b013e3283347bfe.

13. Nishizawa T, Suzuki H, Hosoe N, Ogata H, Kanai T, Yahagi N. Dexmedetomidine vs propofol for gastrointestinal endoscopy: a metaanalysis. United European Gastroenterol J. 2017;5(7):1037-45. https:/doi.org/ 10.1177/2050640616688140.

14. Amri P, Nahrini S, Hajian-Tilaki K, Hamidian M, Alipour SF, Hamidi SH, et al. Analgesic effect and hemodynamic changes due to dexmedetomidine versus fentanyl during elective colonoscopy: a double-blind randomized clinical trial. Anesth Pain Med. 2018;8(6):e81077. https://doi.org/10.5812/ aapm.81077.

15. Edokpolo LU, Mastriano DJ, Serafin J, Weedon JC, Siddiqui MT, Dimaculangan DP. Discharge readiness after propofol with or without dexmedetomidine for colonoscopy: a randomized controlled trial. Anesthesiology. 2019;131(2):279-86. https://doi.org/10.1097/ALN. 0000000000002809

16. Yildiz M, Tavlan A, Tuncer S, Reisli R, Yosunkaya A, Otelcioglu S. Effect of dexmedetomidine on haemodynamic responses to laryngoscopy and intubation : perioperative haemodynamics and anaesthetic requirements. Drugs R D. 2006; 7(1):43-52. https://doi.org/10.2165/00126839-200607010-00004.

17. Bekker AY, Basile J, Gold M, Riles T, Adelman M, Cuff G, et al. Dexmedetomidine for awake carotid endarterectomy: efficacy, hemodynamic profile, and side effects. J Neurosurg Anesthesiol. 2004;16(2): 126-35. https://doi.org/10.1097/00008506-200404000-00004.

18. Ramsay MA, Luterman DL. Dexmedetomidine as a total intravenous anesthetic agent. Anesthesiology. 2004;101(3):787-90. https://doi.org/10. 1097/00000542-200409000-00028.

19. Cortinez LI, Hsu YW, Sum-Ping ST, Young C, Keifer JC, Macleod D, et al. Dexmedetomidine pharmacodynamics: part ii: crossover comparison of the analgesic effect of dexmedetomidine and remifentanil in healthy volunteers. Anesthesiology. 2004;101(5):1077-83. https://doi.org/10.1097/ 00000542-200411000-00006.

20. Liu Y, Liang F, Liu X, Shao X, Jiang N, Gan X. Dexmedetomidine reduces perioperative opioid consumption and postoperative pain intensity in neurosurgery: a meta-analysis. J Neurosurg Anesthesiol. 2018;30(2):146-55. https://doi.org/10.1097/ANA.0000000000000403.

21. Wilhelm W, Schlaich N, Harrer J, Kleinschmidt S, Muller M, Larsen R. Recovery and neurological examination after remifentanil-desflurane or fentanyl-desflurane anaesthesia for carotid artery surgery. Br J Anaesth. 2001;86(1):44-9. https://doi.org/10.1093/bja/86.1.44.

22. Bailey PL, Egan TD, Stanley TH. Intravenous opioid anesthetics. In: Miller RD, editor. Anesthesia. 5th ed. Philadelphia: Churchill Livingstone; 2001.

23. Zhao G, Yin X, Li Y, Shao J. Continuous postoperative infusion of remifentanil inhibits the stress responses to tracheal extubation of patients under general anesthesia. J Pain Res. 2017;10:933-9. https://doi.org/10.2147/ JPR.S123423.

24. Glass PS, Hardman D, Kamiyama Y, Quill TJ, Marton G, Donn KH, et al. Preliminary pharmacokinetics and pharmacodynamics of an ultra-shortacting opioid: Remifentanil (gi87084b). Anesth Analg. 1993;77(5):1031-40. https://doi.org/10.1213/00000539-199311000-00028.

25. Ebert TJ, Hall JE, Barney JA, Uhrich TD, Colinco MD. The effects of increasing plasma concentrations of dexmedetomidine in humans. Anesthesiology. 2000;93(2):382-94. https://doi.org/10.1097/00000542-200008000-00016.

26. Souter MJ, Rozet I, Ojemann JG, Souter KJ, Holmes MD, Lee L, et al. Dexmedetomidine sedation during awake craniotomy for seizure resection: effects on electrocorticography. J Neurosurg Anesthesiol. 2007;19(1):38-44. https://doi.org/10.1097/01.ana.0000211027.26550.24.

\section{Publisher's Note}

Springer Nature remains neutral with regard to jurisdictional claims in published maps and institutional affiliations. 